\title{
Simulating Cross-Contamination of Cooked Pork with Salmonella enterica from Raw Pork through Home Kitchen Preparation in Vietnam
}

\author{
Sinh Dang-Xuan ${ }^{1,2,3} \mathbb{0}$, Hung Nguyen-Viet ${ }^{1,3,4,5}$, Phuc Pham-Duc ${ }^{1}$, Delia Grace ${ }^{6} \mathbb{(}$, \\ Fred Unger ${ }^{3}$, Nam Nguyen-Hai ${ }^{1}$, Thanh Nguyen-Tien ${ }^{7}$ and Kohei Makita ${ }^{2, *(1)}$ \\ 1 Center for Public Health and Ecosystem Research, Hanoi University of Public Health, 1A Duc Thang Road, \\ Duc Thang Ward, North Tu Liem District, Hanoi 100000, Vietnam; dxs@huph.edu.vn (S.D.-X.); \\ H.Nguyen@cgiar.org (H.N.-V.); pdp@vohun.org (P.P.-D.); nam.global247@gmail.com (N.N.-H.) \\ 2 Veterinary Epidemiology Unit, School of Veterinary Medicine, Rakuno Gakuen University, \\ 582 Bunkyodai Midorimachi, Ebetsu, Hokkaido 069-8501, Japan \\ 3 International Livestock Research Institute, 298 Kim Ma Street, Hanoi 100000, Vietnam; F.Unger@cgiar.org \\ 4 Department of Epidemiology and Public Health, Swiss Tropical and Public Health Institute (Swiss TPH), \\ 57 Socinstrasse, 4002 Basel, Switzerland \\ 5 University of Basel, Socinstrasse 57, 4002 Basel, Switzerland \\ 6 International Livestock Research Institute, 30709 Naivasha Street, Nairobi 00100, Kenya; \\ D.GRACE@cgiar.org \\ 7 National Institute of Veterinary Research, 86 Truong Chinh, Hanoi 100000, Vietnam; ntt3180@gmail.com \\ * Correspondence: kmakita@rakuno.ac.jp; Tel.: +81-11-388-4761
}

Received: 3 September 2018; Accepted: 15 October 2018; Published: 22 October 2018

\begin{abstract}
Pork is the most commonly consumed meat in Vietnam, and Salmonella enterica is a common contaminant. This study aimed to assess potential S. enterica cross-contamination between raw and cooked pork in Vietnamese households. Different scenarios for cross-contamination were constructed based on a household survey of pork handling practices (416 households). Overall, $71 \%$ of people used the same knife and cutting board for both raw and cooked pork; however, all washed their hands and utensils between handling raw and cooked pork. The different scenarios were experimentally tested. First, S. enterica was inoculated on raw pork and surfaces (hands, knives and cutting boards); next, water used for washing and pork were sampled to identify the presence and concentration of S. enterica during different scenarios of food preparation. Bootstrapping techniques were applied to simulate transfer rates of S. enterica cross-contamination. No cross-contamination to cooked pork was observed in the scenario of using the same hands with new cutting boards and knives. The probability of re-contamination in the scenarios involving re-using the cutting board after washing was significantly higher compared to the scenarios which used a new cutting board. Stochastic simulation found a high risk of cross-contamination from raw to cooked pork when the same hands, knives and cutting boards were used for handling raw and cooked pork (78\%); when the same cutting board but a different knife was used, cross-contamination was still high (67\%). Cross-contamination between was not seen when different cutting boards and knives were used for cutting raw and cooked pork. This study provided an insight into cross-contamination of S. enterica, given common food handling practices in Vietnamese households and can be used for risk assessment of pork consumption.
\end{abstract}

Keywords: cross-contamination; pork; Salmonella enterica; simulation; Vietnam

\section{Introduction}

Foodborne diseases (FBD) are a major health problem and contribute to reduced economic productivity $[1,2]$. The first global assessment found the health burden of FBD was comparable to that 
of malaria, tuberculosis or HIV / AIDS [2]. In Vietnam, 1781 food poisoning outbreaks were reported between 2006 and 2015 affecting 58,622 people and causing 412 deaths [3]. The actual number of cases is likely to be far higher as under-reporting of FBD is common [4].

Pork and pork products are the most commonly consumed meat in Vietnam [5]. They are also an important source of Salmonella, second to eggs and poultry meat [4,6,7]. In Vietnam, most pork $(80 \%)$ is produced by smallholders and sold in informal markets (open air with limited infrastructure and no cold chain) [8]. Swine commonly harbor Salmonella without showing clinical signs [9-11] and are one of the main reservoirs of human salmonellosis. Studies in Vietnam have found Salmonella in the feces of apparently healthy pigs, with one study reporting a prevalence of $5.2 \%$ [12]. Other studies have reported prevalence ranging from $38.9 \%$ to $49.4 \%$ in feces collected at slaughterhouses $[13,14]$. Reported prevalence on carcasses in slaughterhouses in Vietnam varies from $15.5 \%$ to $95.7 \%$ [14-17]. The prevalence of Salmonella on pork products sold in wet markets in Vietnam ranges from $32.8 \%$ to $69.9 \%[14,16,18,19]$. The general increase in prevalence along the chain suggests that cross-contamination occurs, and a report suggests that $46.7 \%$ of cross-contamination occurs during transportation to the market, which is often un-hygienic (e.g., closed containers are not used, and transport is not clean) and at the market itself [17].

Information on the prevalence of S. enterica in household pork in Vietnam is not available, partly due to ethical and practical challenges with collecting data. During food handling and preparation at home, microorganisms in raw foods can be transferred directly from hands, other surfaces, equipment or utensils to cooked food [20]. Household food preparation may be riskier than commercial food establishment preparation, due to less hygienic handling [21].

Microbiological food safety risk assessment is a powerful tool to understanding the magnitude of health risks from pathogenic bacteria present in foods [22,23]. As part of this, transfer experiments can provide data allowing risk assessment steps to be better described and modeled [24]. This study was designed to gain knowledge about levels of $S$. enterica transferred during pork preparation in home kitchens and support a risk assessment of Salmonella in pork products in Vietnam. The information generated in this study has been utilized in a risk assessment published recently [14], which showed that cross-contamination of Salmonella from raw to cooked pork at Vietnamese household was one of the most important factors influencing salmonellosis incidence.

\section{Materials and Methods}

\subsection{Household Survey on Hygiene Management When Cooking Pork}

In 2013, a total of 416 households in the Hung Yen and Nghe An provinces (208 in each province) were visited and interviews were conducted using a structured questionnaire on risk management practices when preparing pork. From these two provinces, three consumer areas representing rural, peri-urban and urban were selected for the study; from each study area, six towns and six rural communes were then included in the final research. Within the areas of study, households were randomly selected and one representative adult member (aged above 16) per household, usually the housewife, participated in the interview, as previously described by Nga et al. [25]. This interview included questions about diet, food access, food consumption, and food safety knowledge during handling practices under the pork safety project, PigRISK [26].

\subsection{Preparation of Salmonella Culture}

Previous studies have shown, Salmonella Typhimurium, Salmonella Derby and Salmonella London to be the most common serovars in pig carcasses and retailed pork in Vietnam [12,13,27]. These serovars of $S$. enterica, isolated from pig carcasses and retailed pork in a recent investigation by Dang-Xuan [27], were used to make an inoculation medium. First, each serovar was recovered and then cultured separately in a $150 \mathrm{~mL}$-conical flask containing $50 \mathrm{~mL}$ Buffered Peptone Water (BPW) (Merck, Darmstadt, Germany) at $37^{\circ} \mathrm{C}$ overnight (without agitation). The following day, Salmonella 
concentration was determined applying a plate count technique using Xylose Lysine Desoxycholate (XLD, Merck) agar for each cultured medium. Duplicate plates were made by spreading $0.1 \mathrm{~mL}$ of cultured BPW, diluted 10-fold with Maximum Recovery Diluent (MRD, Merck), on XLD plates and incubated at $37^{\circ} \mathrm{C}$ for $20-24 \mathrm{~h}$. After determining the Salmonella concentration, the culture was diluted to a concentration of $10^{5} \mathrm{CFU} / \mathrm{mL}$. Following this $5 \mathrm{~mL}$ of medium containing each incubated serovar of Salmonella with $10^{5} \mathrm{CFU} / \mathrm{mL}$ were mixed, and $15 \mathrm{~mL}$ of the medium prepared. Then, MRD $(90 \mathrm{~mL})$ was added to $10 \mathrm{~mL}$ of the inoculated medium to achieve a concentration of $10^{4} \mathrm{CFU} / \mathrm{mL}$ medium $(100 \mathrm{~mL})$, which was then used to inoculate the pork.

\subsection{Pork Preparation}

Fresh cut pork was purchased immediately after splitting and deboning at a slaughterhouse in the early morning and prior to carcass transportation to the market. The sirloin and/or shoulders (containing both lean and fat areas) were selected. To minimize Salmonella contamination, sterile knives and gloves were used to cut the pork and remove the outer surface of the selected part without removing all subcutaneous and intermuscular fat. Twelve pork pieces (six sirloin and six shoulder pieces) weighing between $500 \pm 40 \mathrm{~g}$ (approximately $14 \times 6 \times 5 \mathrm{~cm} \pm 2 \mathrm{~cm}$ ), from two different carcasses were cut and placed into individual sterile plastic bags and sealed. The pork specimens were kept cool and transported to the laboratory within three hours of collection to perform the experiments. At the laboratory, each pork piece was weighed and prepared for Salmonella inoculation.

\subsection{Inoculation of Pork}

Based on the weight of each pork piece, Salmonella culture (concentration of $10^{4} \mathrm{CFU} / \mathrm{mL}$ ) was inoculated at a rate of $10 \mathrm{CFU} / \mathrm{g}$ of S. enterica. This concentration was based on a previous study measuring the Salmonella contamination range in marketed pork [27]. Approximately $500 \pm 40 \mu \mathrm{L}$ of the culture ( $1 \mu \mathrm{L}$ for $1 \mathrm{~g}$ of the pork) was dispensed on the surface of the pork piece using a filter tip and pipette (Thermo Scientific, Madison, WI, USA). This covered the entire surface of the pork piece. The inoculated pork pieces were kept on a table at an ambient temperature $\left(26-30{ }^{\circ} \mathrm{C}\right)$ for $30 \mathrm{~min}$ to allow cell attachment prior to starting the experiments as described by Ravishankar et al. [28].

\subsection{Pork and Equipment Washing}

Pork was washed twice in a basin with Salmonella-free water using bare hands. Washed pork then was placed on a cutting board and cut into 2-3 smaller pieces (approximately $150 \mathrm{~g}$ per piece, which is the size of $5 \times 6 \times 5 \mathrm{~cm} \pm 2 \mathrm{~cm}$ ). Washing of hands, knives and cutting boards was done separately using Salmonella-free water, dish-washing detergent and a dish cloth. Following washing, equipment was air dried for $75 \mathrm{~min}$ and then used in subsequent experimental steps. The boiled pork pieces were sliced into pieces of two to four millimeters thick with the length and width measuring were approximate two and five centimeters, respectively, as would be done when preparing pork for serving.

\subsection{Sampling}

Both hands (surface, palms, fingers, webbing), $25 \mathrm{~cm}^{2}$ of both sides of the knife and $25 \mathrm{~cm}^{2}$ of the cutting board surface were swabbed using sterile pre-moistened gauze. The surface samples from hands, knives, and cutting boards were collected immediately after washing raw pork twice and just before slicing cooked pork. Pork wash-water samples (approximately $30-40 \mathrm{~mL}$ per sample) were aseptically collected after twice washing the raw pork. Both raw and cooked pork samples were collected using sterile scalpels and forceps. Raw pork was sampled prior to pork being placed into a pot of boiling water. Cooked pork was sampled directly after boiling. The cooked pork slice was sampled immediately after slicing. 


\subsection{Design of Cross-Contamination Studies}

This study was designed to quantify the potential for transfer of S. enterica in home kitchens, from raw to cooked pork, via hands, knife (with a plastic handle and stainless-steel blade), and a wooden cutting board. The experimental design followed four main steps: (1) Raw pork was artificially inoculated with S. enterica; (2) The inoculated pork was then washed twice using Salmonella-free water (Lavie Ltd., Nestlé Water, DongNai, Vietnam); (3) It was then cut into smaller pieces and boiled in a pot with 2-2.5 L of water for $15 \mathrm{~min}$; and (4) Following cooking, the pork was sliced. Four different preparation techniques (scenarios) were investigated based on cooking practice information obtained from the household survey (Figure 1). The Salmonella concentration in raw washed pork and occurrence of cross-contamination on hands, knives, and cutting boards was measured (Table 1). The contamination status and the level of Salmonella were also measured on the cooked pork. The experiment was carried out in triplicate in three groups, and repeated three times, equating to nine experimental trials for each scenario.

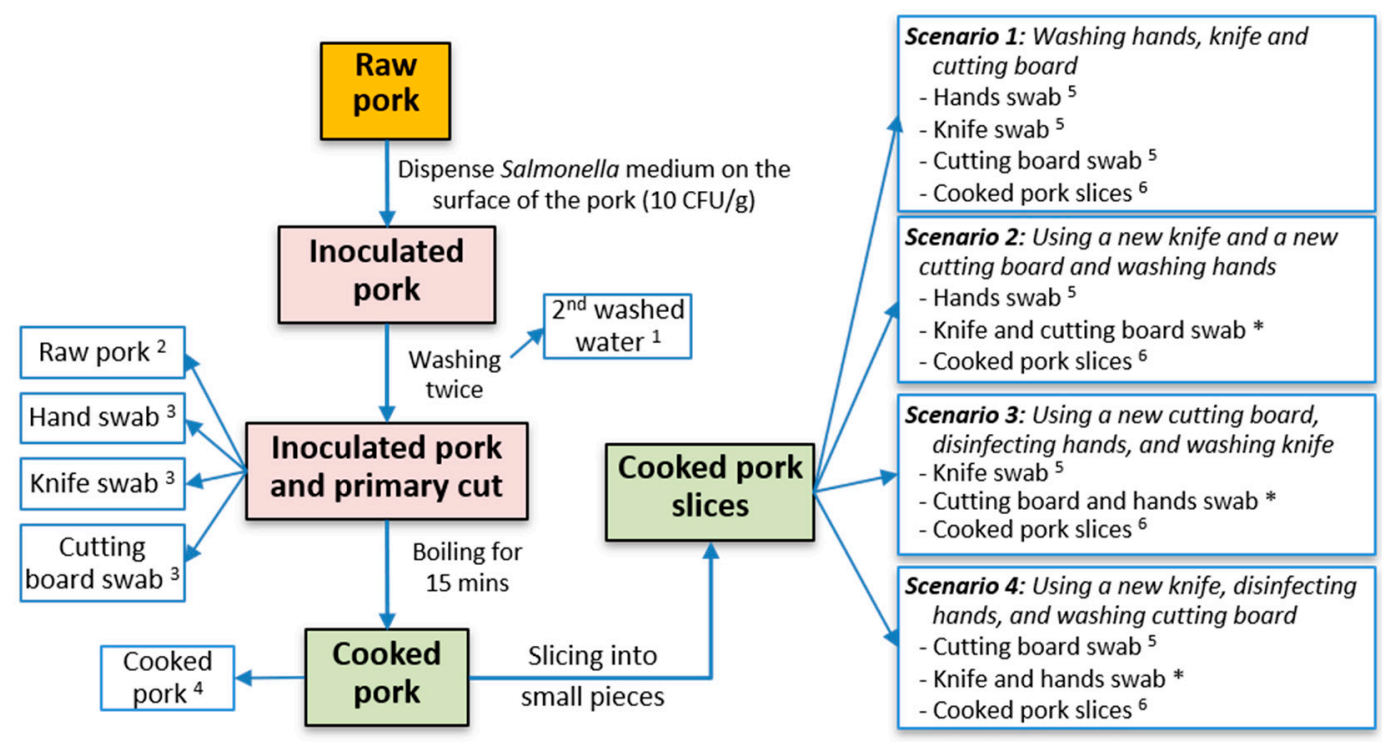

Figure 1. Steps and scenarios in experiment of Salmonella enterica cross-contamination. Timing associated with the steps: ${ }^{1}$ after washing inoculated pork twice, ${ }^{2}$ just before boiling after washing pork twice, ${ }^{3}$ after primary cut of pork and washing once, ${ }^{4}$ after boiling pork (wait until cool down) without any process, ${ }^{5}$ just before slicing cooked pork, ${ }^{6}$ after finishing slicing the cooked pork pieces, and ${ }^{*}$ disinfection before slicing.

Table 1. Investigation of Salmonella enterica during cross-contamination experiments.

\begin{tabular}{lll}
\hline \multicolumn{1}{c}{ Sampling Points } & Sample Type & Data \\
\hline $\begin{array}{l}\text { Measuring remaining Salmonella levels after washing } \\
\text { contaminated pork }\end{array}$ & $\begin{array}{l}\text { Water for } \\
\text { washing } \\
\text { recovered } \\
\text { Water used for washing }\end{array}$ & Qualitative $^{1}$ \\
Raw pork after being washed twice & MPN $^{2}$ \\
\hline $\begin{array}{l}\text { Testing whether cross-contamination with Salmonella occurs } \\
\text { after cutting raw pork }\end{array}$ & Surface swab \\
$\begin{array}{l}\text { Hands } \\
\text { Knife }\end{array}$ & $\begin{array}{l}\text { Surface swab } \\
\text { Cutting board }\end{array}$ & $\begin{array}{l}\text { Qualitative } \\
\text { Qualitative } \\
\text { Qualitative }\end{array}$ \\
\hline $\begin{array}{l}\text { Ensuring Salmonella was inactivated } \\
\text { Cooked pork immediately after cooking }\end{array}$ & Purk piece & Qualitative \\
\hline
\end{tabular}


Table 1. Cont.

\begin{tabular}{|c|c|c|}
\hline Sampling Points & Sample Type & Data \\
\hline \multicolumn{3}{|c|}{$\begin{array}{l}\text { Measuring the level of cross-contamination with Salmonella } \\
\text { when handling the cooked pork in different scenarios } \\
\text { Scenario 1: Washing hands, knife and cutting board }\end{array}$} \\
\hline Hands before slicing & Surface swab & Qualitative \\
\hline Knife before slicing & Surface swab & Qualitative \\
\hline Cutting board before slicing & Surface swab & Qualitative \\
\hline Pork after slicing & Pork slice & $\mathrm{MPN}$ \\
\hline \multicolumn{3}{|c|}{$\begin{array}{l}\text { Scenario 2: Using a new knife and a new cutting board and washing } \\
\text { hands }\end{array}$} \\
\hline Hands before slicing & Surface swab & Qualitative \\
\hline Pork after slicing & Pork slice & $\mathrm{MPN}$ \\
\hline \multicolumn{3}{|c|}{$\begin{array}{l}\text { Scenario 3: Using a new cutting board, disinfecting hands, and washing } \\
\text { knife }\end{array}$} \\
\hline Knife before slicing & Surface swab & Qualitative \\
\hline Pork after slicing & Pork slice & MPN \\
\hline \multicolumn{3}{|c|}{$\begin{array}{l}\text { Scenario 4: Using a new knife, disinfecting hands, and washing } \\
\text { cutting board }\end{array}$} \\
\hline Cutting board before slicing & Surface swab & Qualitative \\
\hline Pork after slicing & Pork slice & $\mathrm{MPN}$ \\
\hline
\end{tabular}

\subsection{Cross-Contamination Scenarios}

According to the household survey, all respondents typically washed pork, hands, knives and wooden cutting boards, but there were differences in whether separate knives and/or cutting boards were used for raw and cooked pork. Scenario 1, representing the most common practice reported in the household survey (see Section 3), examined the degree of cross-contamination when no separate knives and cutting boards were used. Scenarios $2-4$ utilized different combinations of washing equipment and hands (Table 1). The details of scenario 1 are as follows: after the raw pork was washed and cut, the knife, cutting board and hands were washed in a basin with clean water at ambient temperature (26-30 $\left.{ }^{\circ} \mathrm{C}\right)$ using dish-washing detergent (Sunlight, Unilever Co. Ltd., Ho Chi Minh, Vietnam) and a dish cloth (Suka, Luoisoi Co. Ltd., Ho Chi Minh, Vietnam) for approximately three minutes. All dish cloths used were autoclaved prior to the experiments. The washed knife and cutting board were then reused to slice the cooked pork by the same person. In scenario 2, after the washed raw pork was cut, hands were washed with clean water using dish-washing detergent and a dish cloth, and a new cutting board and new knife were used to slice cooked pork by the same person. In scenario 3 , after washed raw pork was cut, the knife was washed in clean water using dish-washing detergent and a dish cloth, and hands were disinfected using both 70\% ethanol (Con70, Tien Dung Co., Ltd., Ho Chi Minh, Vietnam) and instant hand sanitizer (Purell, Akron, OH, USA). Then a new cutting board and the washed knife were used to slice the cooked pork. In scenario 4, after the washed raw pork was cut, the cutting board was washed using clean water, dish detergent and a dish cloth, and hands were disinfected as described in scenario 3. Cooked pork was sliced on the washed cutting board using a new knife.

\subsection{Microbiological Tests}

Salmonella detection was carried out according to the ISO-6579: 2002 procedure [29]. In the pre-enrichment step, swabs or $10 \mathrm{~mL}$ of liquid samples were added up to $100 \mathrm{~mL}$ BPW for homogenization. Pork samples weighing $25 \mathrm{~g}$ were homogenized in $225 \mathrm{~mL}$ BPW. For Salmonella 
enumeration in pork samples, a 3 tube-Most Probable Number (MPN) method was used following ISO/TS-6579-2: 2012 [30]. In the pre-enrichment step of MPN, series of three tubes per dilution of 1-0.1-0.01 g and 10-1-0.1 g were prepared for the incubation of raw and cooked pork, respectively. Further steps of Salmonella detection and enumeration were previously described in Dang-Xuan [27].

\subsection{Data Analysis and Modeling}

All data were digitized in Excel 2010 (Microsoft, Redmond, WA, USA) spreadsheets. Descriptive statistics were performed using Chi-squared test and Fisher's exact test to compare the proportions of samples contaminated with Salmonella using R version 3.3.2 (R Core team, Vienna, Austria, 2015).

To estimate the distributions of Salmonella concentration on pork slice in the scenarios, both non-parametric and parametric bootstrapping techniques were used. Bacterial concentration was measured as MPN/g (note that MPN/g and CFU/g hereafter is at the original bacterial count scale), and thus follows Log-Normal distribution with the mean MPN/g, and the standard deviation in $\log _{10}$ scale $\left(s d_{\log 10}\right)$ determined as shown in Equation (1) [31,32]:

$$
s d_{\log 10}=0.55 \sqrt{\log _{10} \alpha}=0.55 \sqrt{\log _{10} 10}=0.55
$$

where $\alpha$ is dilution ratio, ten. For the parametric bootstrapping in $\mathrm{R}, \operatorname{rnorm}\left(1, \ln \mu, s d_{\ln }\right)$ function was used to sample a single value from Log-Normal distribution, where $\ln \mu$ is the natural logarithm of the MPN, and $s d_{\ln }$ is the standard deviation in the natural logarithm scale. $s d_{\ln }$ was calculated using natural logarithm (ln) as Equation (2):

$$
s d_{\ln }=\ln 10^{s d_{\log 10}}=\ln 10^{0.55}=1.266422
$$

In each scenario, a distribution of an MPN result was randomly selected at equal probability of selection among the MPN results of Salmonella positive samples for the type of the sample of interest. A value was randomly sampled from the distribution selected. For the mean MPN/g less than 0.03 , a value was randomly selected from non-informative uniform distribution between natural logarithm of $0.01 \mathrm{MPN} / \mathrm{g}(-4.60517)$ and $0.03 \mathrm{MPN} / \mathrm{g}(-3.50656)$, and exponential of the value was calculated. This process was iterated 5000 times using a for-loop function written in $\mathrm{R}$ to obtain the integrated distribution for each scenario. The median, 2.5th and 97.5th values of the stored 5000 samples were obtained, and Log-Normal distribution was fit to the simulated sample data using a maximum likelihood method in fitdist() function in the fitdistrplus package [33] to obtain the mean and standard deviation. For the presentation of the distributions, kernel density was calculated in density() function using the simulated sample data and plotted using R.

The reduction rate in Salmonella CFU/g was modelled by dividing the value (CFU/g) sampled as above by $10 \mathrm{CFU} / \mathrm{g}$, which gave the initial Salmonella concentration inoculated on the raw pork. The calculation of reduction rate was iterated 5000 times to determine distributions. The distribution of reduction rate was presented using a histogram.

As there were two MPN values which gave a result of $11 \mathrm{MPN} / \mathrm{g}$ in scenario 1 and 4, exceeding the inoculation level, above simulations on $\mathrm{CFU} / \mathrm{g}$ and reduction rate distributions were performed without these MPN values and with these two values named worst case scenarios.

\subsection{Ethical Statement}

The experiments and Salmonella analysis were carried out at the Department of Veterinary Hygiene of National Institute of Veterinary Research (Hanoi, Vietnam). All volunteers gave informed consent for their participation in the study. Ethical approval of this study (No. 148/2012/YTCC-HD3) was obtained from the ethical committee of the Hanoi University of Public Health. This research was a part of the PigRISK project and the Taskforce for Food Safety Risk Assessment in Vietnam, funded by ACIAR [26]. 


\section{Results}

\subsection{Household Survey}

Most (87\%) households reported that they washed their hands and equipment after handling raw pork with ambient temperature water, while the rest using hot water (Table 2). The most common practice in both provinces was to use the same knife and cutting board, washed in between, for both raw and cooked pork $(71.4 \%, 297 / 416)$. Use of separate knives and cutting boards for raw and cooked pork was less common $(16.1 \%, 67 / 416)$.

Table 2. Use of separate equipment between raw and cooked pork, and water temperature for washing hands and equipment after handling raw pork in cooking pork slice in households in Hung Yen and Nghe An provinces.

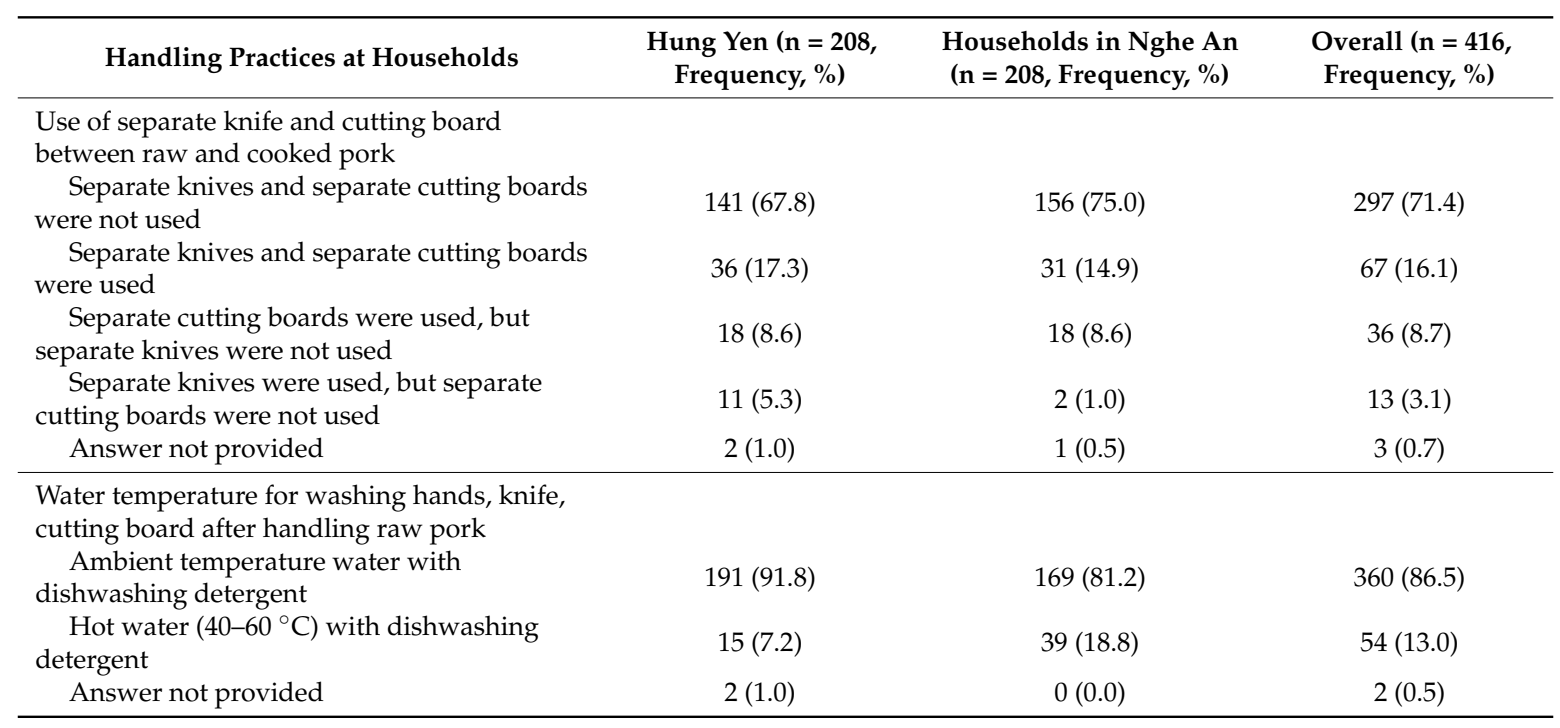

\subsection{Effect of Washing Twice on the Prevalence and Salmonella Concentration in Raw Pork}

After twice washing raw pork, Salmonella was isolated from all nine samples with no reduction in prevalence observed. Table 3 shows the Salmonella concentrations of the raw pork samples. The simulated CFU/g of Salmonella in raw pork after washing twice was 1.56 (median 0.44; 95\% CI: 0.03-10.14, Figure 2). Figure 3 shows the Salmonella concentration reduction rate measured on washed raw pork. The mean reduction rate of raw pork by washing twice in water was $84.4 \%$ (median 95.6\%; 95\% CI: $-1.8-99.7 \%)$. These results suggested that washing raw pork can reduce bacteria levels but cannot eliminate Salmonella from the surface.

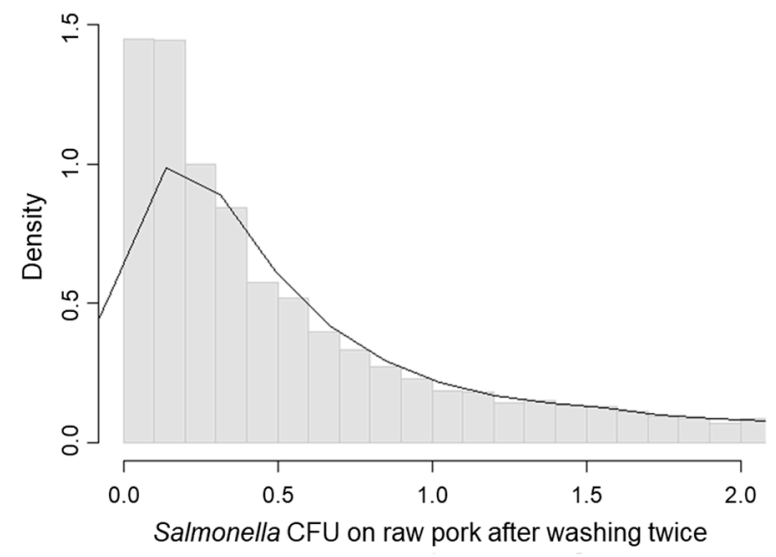

Figure 2. Distribution of Salmonella concentration (CFU/g) on raw pork after washing twice. 
Table 3. Frequencies of MPN/g results categorized in MPN ranges and integrated Salmonella concentration distributions as mean, median, and confidence interval of CFU/g for washed raw pork and cooked pork slice in different cooking scenarios.

\begin{tabular}{|c|c|c|c|c|c|c|}
\hline \multirow{2}{*}{ Scenario } & \multicolumn{4}{|c|}{ Number of Samples in Salmonella MPN/g ${ }^{1}$ Ranges } & \multirow{2}{*}{$\begin{array}{c}\text { Mean CFU/g }{ }^{2} \\
\text { (median) }\end{array}$} & \multirow{2}{*}{$95 \% \mathrm{CI}$} \\
\hline & $<0.03$ & $0.03-0.30$ & $0.31-3.0$ & $>3.0$ & & \\
\hline $\begin{array}{l}\text { Raw pork after washing twice } \\
\text { Cooked pork slice }\end{array}$ & 0 & 1 & 8 & 0 & $1.56(0.44)$ & $0.03-10.14$ \\
\hline Scenario 1 & 1 & 4 & 1 & 0 & $0.71(0.12)$ & $0.00-5.96$ \\
\hline Scenario $1^{3}$ & 1 & 4 & 1 & 1 & $4.21(0.16)$ & $0.00-40.20$ \\
\hline Scenario 3 & 1 & 1 & 0 & 0 & $0.12(0.05)$ & $0.00-0.67$ \\
\hline Scenario 4 & 0 & 3 & 2 & 0 & $2.49(0.44)$ & $0.01-17.78$ \\
\hline Scenario $4^{3}$ & 0 & 3 & 2 & 1 & $5.79(0.71)$ & $0.01-47.06$ \\
\hline
\end{tabular}

${ }^{1}$ Most Probable Number, ${ }^{2}$ Colony Forming Unit, ${ }^{3}$ Scenarios referred to the simulations on CFU/g and reduction rate distributions that were performed with two MPN values, which resulted as $11 \mathrm{MPN} / \mathrm{g}$ in scenario 1 and 4 , exceeding the inoculation level. Scenario 1-Washing hands, the knife and the cutting board, Scenario 3-Using a new cutting board, disinfecting hands, and washing the knife, Scenario 4-Using a new knife, disinfecting hands, and washing the cutting board.

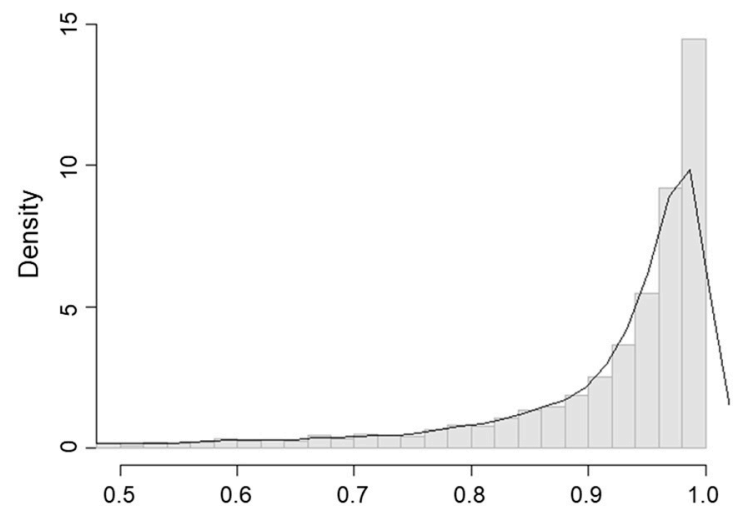

Figure 3. Reduction rate of Salmonella concentration in CFU/g after washing raw pork twice.

\subsection{Cross-Contamination of Equipment and Hands with Salmonella from Raw Pork}

Table 4 shows the proportions of sliced cooked pork, equipment, and hands for which Salmonella was transferred from raw to cooked pork (cross-contamination). Although raw pork was washed twice, cross-contamination with Salmonella from pork to hands, knives and cutting boards was common (78\%, $78 \%$, and $100 \%$, respectively). Eight out of nine wash water samples were positive for Salmonella.

Table 4. Proportions of cooked pork slice, hands, equipment and wash water on which cross-contamination with Salmonella occurred during the experiments.

\begin{tabular}{lccc}
\hline \multicolumn{1}{c}{ Type of Sample } & $\begin{array}{c}\text { Samples Cross-Contaminated } \\
(\mathbf{n}=\mathbf{9 )}\end{array}$ & $\begin{array}{c}\text { Proportion } \\
\text { Contaminated (\%) }\end{array}$ & 95\% CI \\
\hline $\begin{array}{l}\text { After raw pork handling } \\
\text { Hands }\end{array}$ & 7 & 77.8 & $40.2-96.1$ \\
Knife & 7 & 77.8 & $40.2-96.1$ \\
$\quad$ Cutting board & 9 & 100 & $62.9-100$ \\
$\quad$ Wash water & 8 & 88.9 & $50.7-99.4$ \\
\hline Scenario 1 & & & \\
$\quad$ Cooked pork slice & 7 & 77.8 & $40.2-96.1$ \\
$\quad$ Hands & 3 & 33.3 & $9.0-69.1$ \\
Knife & 4 & 44.4 & $15.3-77.3$ \\
$\quad$ Cutting board & 5 & 55.6 & $22.7-84.7$ \\
\hline Scenario 2 & & & \\
$\quad$ Cooked pork slice & 0 & 0.0 & $0.0-37.1$ \\
$\quad$ Hands & 3 & 33.3 & $9.0-69.1$ \\
\hline
\end{tabular}


Table 4. Cont.

\begin{tabular}{lccc}
\hline Type of Sample & $\begin{array}{c}\text { Samples Cross-Contaminated } \\
(\mathbf{n}=\mathbf{9})\end{array}$ & $\begin{array}{c}\text { Proportion } \\
\text { Contaminated (\%) }\end{array}$ & 95\% CI \\
\hline Scenario 3 & 2 & 22.2 & $3.9-59.8$ \\
$\quad$ Cooked pork slice & 0 & 0.0 & $0.0-37.1$ \\
$\quad$ Knife & & & \\
\hline Scenario 4 & 6 & 66.7 & $30.9-90.9$ \\
$\quad$ Cooked pork slice & 6 & 66.7 & $30.9-90.9$ \\
$\quad$ Cutting board & 6
\end{tabular}

1 Scenario 1-Washing hands, the knife and the cutting board, Scenario 3-Using a new cutting board, disinfecting hands, and washing the knife, Scenario 4-Using a new knife, disinfecting hands, and washing the cutting board.

\subsection{Re-Contamination of Cooked Pork Slices with Salmonella by Equipment and Hands}

After cooking, Salmonella was not isolated from the nine pork samples. Salmonella was eliminated from pork by cooking, through re-contamination of boiled pork occurred in scenarios 1, 3, and 4 (Table 4). In scenario 2, new equipment (knife and cutting board) was used and re-contamination did not occur. The probability of re-contamination was highest in scenario 1, which did not involve use of separate equipment or disinfection of hands $(7 / 9,77.8 \%)$. There was no significant difference in the proportion of re-contamination between the scenarios re-using the cutting board after washing (scenarios 1 and $4, p=1$, Fisher's exact test, Table 4). When the scenarios involving re-using the same cutting board were combined ( 1 and 4$)$, the probability of re-contamination $(72.2 \%)$ was higher than scenarios which used a new cutting board (scenarios 2 and 3) and where re-contamination was $11.1 \%$. The difference between these proportions was found to be significant $\left(x^{2}=11.4, \mathrm{df}=1, p<0.01\right)$.

In scenario 4, (new knife, disinfected hands, and washed cutting board), the Salmonella concentration on cooked pork was the highest (mean CFU/g $=2.49$, Table 3, Figure 4c) followed by the Salmonella concentration on cooked pork in scenarios 1 and 3 (Figure 4a,b). Scenario 4 also had the lowest reduction rate of Salmonella concentration on cooked pork (mean $=75.1 \%$, Table 5, Figure 5c). Scenario 3, which represented the risk of re-contamination through re-use of a knife, showed low probability of re-contamination (mean $=22.2 \%$, Table 4 ), and a higher reduction rate of Salmonella concentration (mean $=98.9 \%$, Table 5, Figure $5 b$ ) compared with scenarios 1 and 4 (Figure 5a,c).

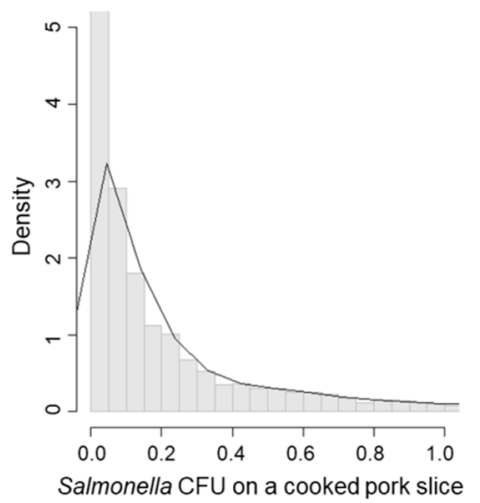

(a)

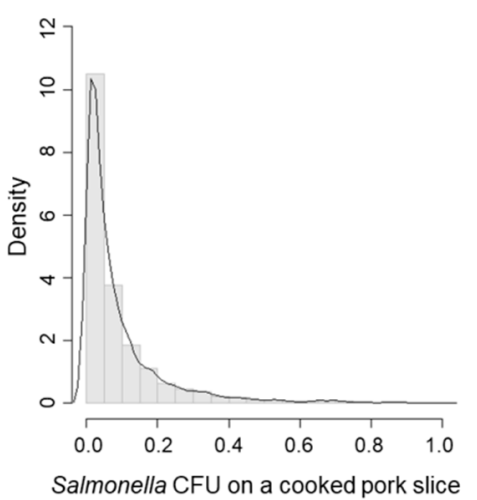

(b)

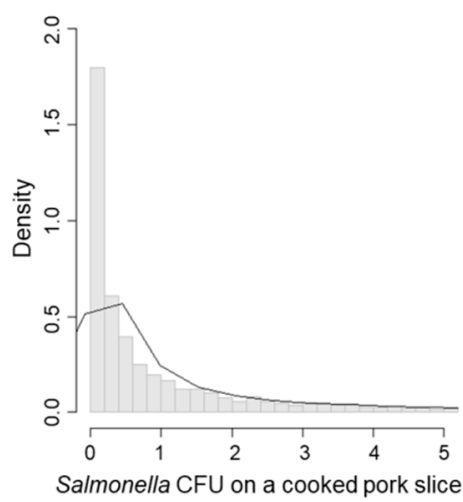

(c)

Figure 4. Salmonella CFU/g on a pork slice due to cross-contamination. (a) Scenario 1-Washing hands, the knife and the cutting board; (b) Scenario 3-Using a new cutting board, disinfecting hands, and washing the knife; (c) Scenario 4-Using a new knife, disinfecting hands, and washing the cutting board. 


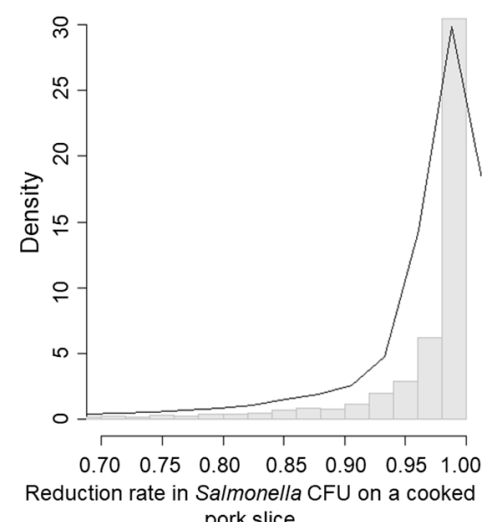

(a)

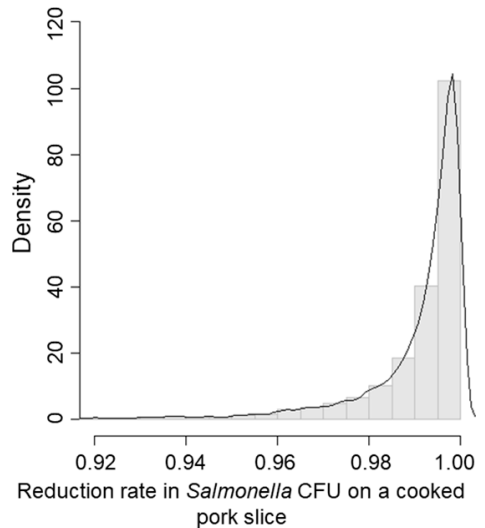

(b)

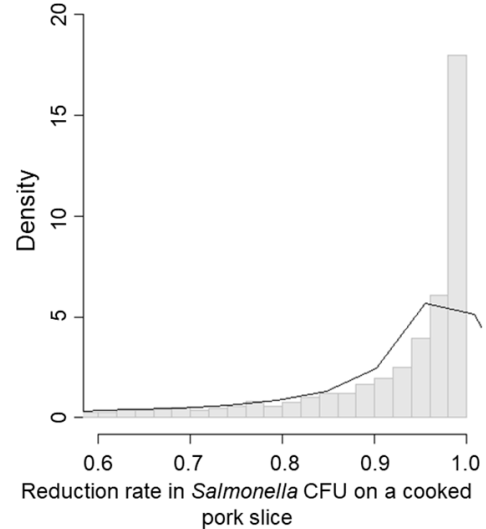

(c)

Figure 5. Reduction rates after Salmonella cross-contamination to cooked pork slice. (a) Scenario 1-Washing hands, the knife and the cutting board; (b) Scenario 3-Using a new cutting board, disinfecting hands, and washing the knife; (c) Scenario 4-Using a new knife, disinfecting hands, and washing the cutting board.

In the two worst case scenarios (that were performed with two MPN values, which resulted as $11 \mathrm{MPN} / \mathrm{g}$ in scenario 1 and 4, exceeding the inoculation level), the mean Salmonella concentration re-contaminated on cooked pork in scenarios 1 (Figure 6a) and 4 (Figure 6b) were $4.21 \mathrm{CFU} / \mathrm{g}$ and $5.79 \mathrm{CFU} / \mathrm{g}$ (Table 3), respectively.

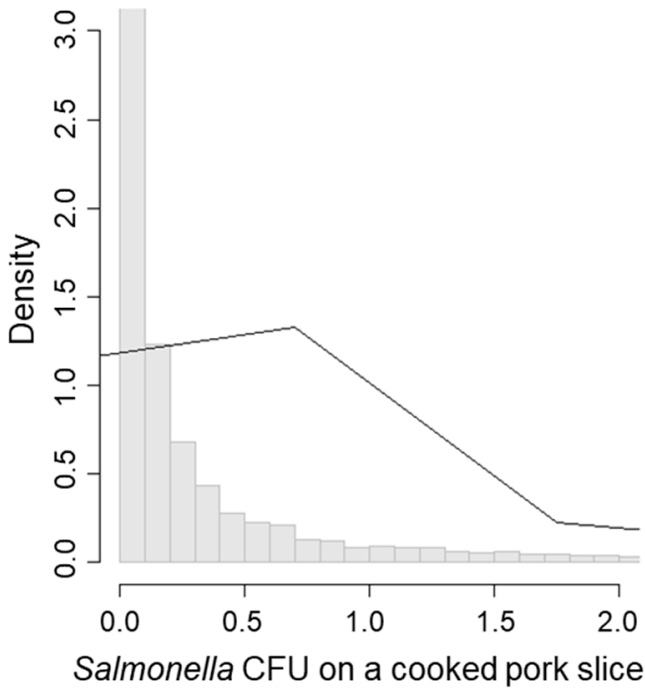

(a)

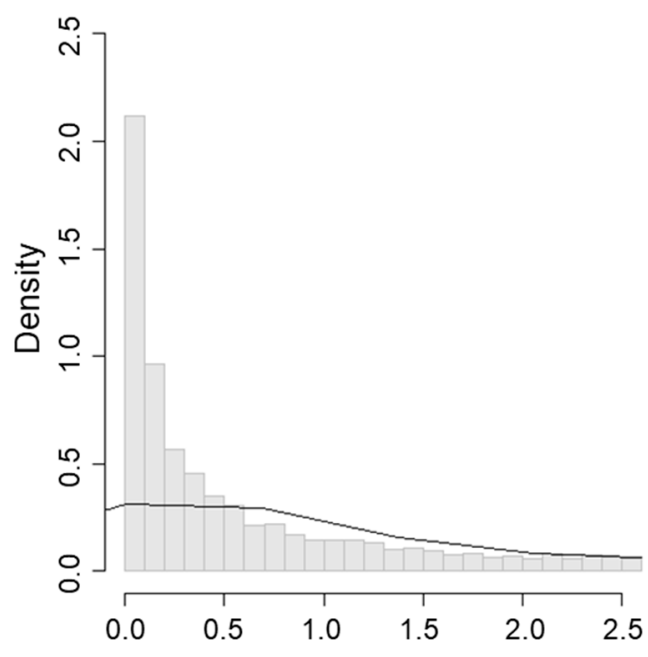

Salmonella CFU on a cooked pork slice

(b)

Figure 6. Worst case scenarios of Salmonella CFU/g on a pork slice due to cross-contamination. (a) Scenario 1-Washing hands, the knife and the cutting board; (b) Scenario 4-Using a new knife, disinfecting hands, and washing the cutting board. Worst case scenarios referred to the simulations on $\mathrm{CFU} / \mathrm{g}$ and reduction rate distributions that were performed with two MPN values, which resulted as $11 \mathrm{MPN} / \mathrm{g}$ in scenario 1 and 4, exceeding the inoculation level.

The probability of cross-contamination in the worst case of scenarios 1 (Figure 7a) and 4 (Figure 7b) were almost $30 \%$ higher compared to their initial scenarios (Table 5). The probabilities of exceeding the initial CFU/g measurement in both scenarios 1 and 4 were $8.2 \%$ and $13.0 \%$, respectively (Table 5). 
Table 5. Reduction rate of Salmonella concentration.

\begin{tabular}{|c|c|c|c|c|c|}
\hline Scenario & Mean Reduction Rate (\%) & Median (\%) & Lower Limit (\%) & Upper Limit (\%) & Exceeded Initial CFU/g (\%) ${ }^{1}$ \\
\hline Scenario 1 & 92.7 & 98.8 & 44.9 & 99.9 & 1.0 \\
\hline Scenario $1^{2}$ & 57.9 & 98.4 & -308.1 & 99.9 & 8.2 \\
\hline Scenario 3 & 98.9 & 99.5 & 93.8 & 99.9 & 0 \\
\hline Scenario $4^{2}$ & 42.1 & 92.9 & -372.6 & 99.9 & 13.0 \\
\hline
\end{tabular}

${ }^{1}$ Colony Forming Unit, ${ }^{2}$ Scenarios referred to the simulations on CFU/g and reduction rate distributions that were performed with two MPN values, which resulted as $11 \mathrm{MPN} / \mathrm{g}$ in scenario 1 and 4, exceeding the inoculation level. Scenario 1-Washing hands, the knife and the cutting board, Scenario 3-Using a new cutting board, disinfecting hands, and washing the knife, Scenario 4-Using a new knife, disinfecting hands, and washing the cutting board.

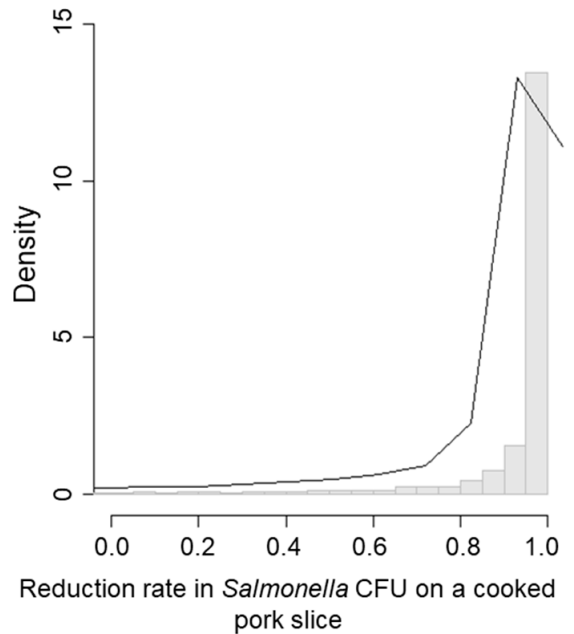

(a)

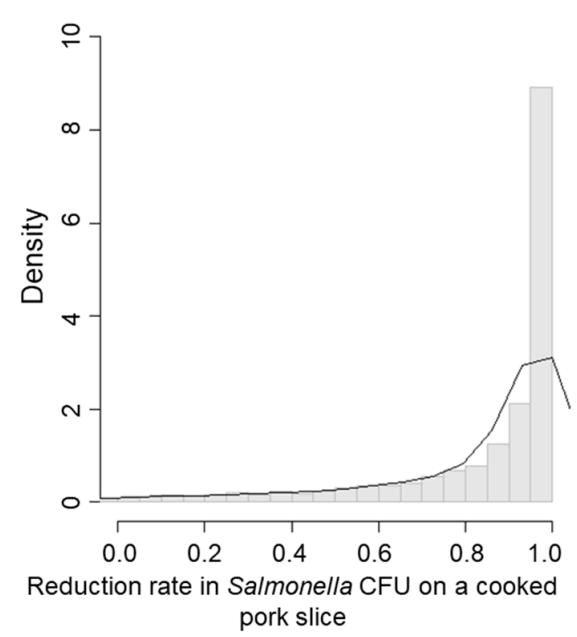

(b)

Figure 7. Reduction rate in CFU/g on a cooked pork slide in worst case scenarios. (a) Scenario 1-Washing hands, the knife and the cutting board; (b) Scenario 4-Using a new knife, disinfecting hands, and washing the cutting board. Worst case scenarios referred to the simulations on CFU/g and reduction rate distributions that were performed with two MPN values, which resulted as $11 \mathrm{MPN} / \mathrm{g}$ in scenario 1 and 4 , exceeding the inoculation level.

\section{Discussion}

In this study, four different household food-handling behavior scenarios investigating Salmonella transmission were examined using cross-contamination experiments. The practices commonly used, supported by a field survey, were found to result in cross-contamination. In this experiment set, cross-contamination mainly occurred through use of same cutting board (scenarios 1 and 4). The practice of using the same utensil and/or cutting board to prepare both raw meats and other foods has been reported in the other countries: $25 \%$ to $83 \%$ of the respondents did this in the USA [21,34]. Such unsafe practices may cause cross-contamination during home food preparation.

The vast majority of salmonellosis cases have been linked to ingesting living Salmonella [35,36]. The results of this study suggest the significant contribution of cutting boards in the establishment of cross-contamination of S. enterica. The use of other utensils, knives and hands in home cooking processes are also known to play an important role in bacterial cross-contamination [37]. As such, washing of surfaces and equipment including cutting board and knives, and hands is reported to reduce bacterial contamination [38]. Use of detergent in washing kitchen equipment and hands also reduces transmission of diarrhea-causing pathogens [39] and is more effective than water alone [40]. However, the results of this study suggest that washing, even using dish detergent, has limited effect on elimination of Salmonella from the surfaces of kitchen equipment and hands (Scenario 1 and 4, $33.3-66.7 \%$, Table 4). We used the same dish detergent for all washing steps, and other types of detergent such as hypochlorite [41] or organic acid [42,43] or hot water at 75 to $80^{\circ} \mathrm{C}$ [43], as well as frequent and careful washing [41] may further reduce the chance of transmission of not only Salmonella 
but also other diarrhea-causing pathogens. Further, this study demonstrated that use of separate equipment between raw and cooked pork should also be encouraged.

The use of an autoclaved dishcloth for drying hands and utensils in this study means levels of cross-contamination was likely lower than real world enactment of these scenarios. Several studies have shown that kitchen dishcloths are often contaminated with bacteria and these would be an additional means of cross-contamination [44].

Remarkably, in the two worst case scenarios in this study, a higher Salmonella concentration than the initial inoculum was found after preparation, indicating microbial growth rather than reduction. An explanation for this may be that wooden cutting boards are known to absorb moisture which allows bacteria to adhere and multiply. Studies have shown that Salmonella can survive in deep cuts on wooden cutting boards [45,46] and that wood is one of the most difficult surfaces to disinfect [41]. Although washing cutting boards was a common practice in the studied areas, this experiment showed that bacteria can remain and be a source of cross-contamination. This finding has been reported in previous studies $[47,48]$. Therefore, future food safety intervention programs in Vietnam should focus on the risk of cross-contamination from cutting boards in home kitchens.

This study used a Bayesian approach, to present uncertainty and variability of Salmonella concentrations and reduction rates as probability distributions, using a limited number of samples. This information, together with the probability of cross-contamination in different hygiene procedures, is particularly useful in the exposure assessment step in risk assessment which usually lacks the data $[20,49]$.

There are some limitations in this study. First, we took swabs from only $25 \mathrm{~cm}^{2}$ of each side of the knife and cooking board, which may underestimate cross-contamination. Second, we assumed no growth of Salmonella during the experiments. As this experiment included time to dry hands and equipment, which is not a common practice between people preparing food, the bacterial concentration presented in this study may be under-estimated. Third, the pork was not washed before it was inoculated with Salmonella. However, cut pork sampling at the slaughterhouse took place aseptically, so it is unlikely that significant Salmonella contamination would have occurred prior to inoculation and have affect the results. Forth, the sample size was relatively small and future study to increase the sample size would reduce the uncertainties in distributions. Fifth, the nature of the food, type of surfaces and level of moisture were reported as important factors influencing on microbial transfer rates [50,51]. Future studies may consider the conditions of time, temperature and surface type related to bacterial growth.

This study provided the first data on the possible occurrence and magnitude of crosscontamination which was used for quantitative risk assessment of Salmonella from household pork consumption in Vietnam [14]. The levels of cross-contamination in different scenarios will allow us to estimate potential risk-mitigating strategies. These findings may aid in promoting improvement in safer food handling practices in households, in addition to supporting risk communication and food safety education for consumers, and to minimize adverse health risk consequences [52,53]. The findings may counter the common misperception that if pork is cooked well before consumption it does not present a risk. The presence of Salmonella in ready-to-eat or cooked food due to cross-contamination has been reported in several studies $[53,54]$ and the findings in our study can also be used for assessing the risks in these foods.

\section{Conclusions}

This study demonstrated that cross-contamination with Salmonella in household kitchens occurs when the same kitchen utensils (especially cutting boards) are used when preparing raw and cooked pork, even if they are washed between. This practice was common in households in Vietnam. On the contrary, no cross-contamination was observed when a different cutting board and knife was used for preparing raw and cooked pork, but this is rarely done in Vietnam. Radical changes in household cooking preparation may reduce the incidence of salmonellosis greatly in the country, and other parts of the world with similar settings. However, such changes may be difficult to promote, and risk 
reduction and adaptation of other options such as using difference types of cutting boards or different washing protocols should be examined.

Author Contributions: S.D.-X., H.N.-V., P.P.-D., T.N.-T. and K.M. designed the study and interpreted the results. K.M. and S.D.-X. analysed the data and drafted the manuscript. D.G. and F.U. took part in the writing of the manuscript and gave substantial comments. S.D.-X., N.N.-H. and T.N.-T. collected test and interview data. All authors read and approved the final manuscript.

Funding: This research was funded by the Swiss Agency for Development and Cooperation through a small grant of the Swiss Embassy in Vietnam and the Australian Centre for International Agricultural Research (ACIAR) grant number: LPS/2010/047, and SDX was supported by Rakuno Gakuen University Guest Researcher Grant and Japan Society for the Promotion of Science (JSPS) RONPAKU Program (R 11717) during analysis and writing phase.

Acknowledgments: This study was a part of the Taskforce for Food Safety Risk Assessment at Hanoi University of Public Health, the PigRISK project funded by the ACIAR, the Consultative Group on International Agricultural Research (CGIAR), Research Program Agriculture for Nutrition and Health (A4NH), and the Swiss Agency for Development and Cooperation (SDC). We thank the volunteers for their participation in the study. The authors thank the researchers at the Veterinary hygiene department, National Institute of Veterinary Research and staff at CENPHER, Hanoi University of Public Health for their assistance with the experiments. The authors thank Ambassador Andrei Motyl and Professor Marcel Tanner for supporting this study and Ms. Kylie Cuthbertson, an Australian volunteer under AVID program funded by the Department of Foreign Affairs and Trade (DFAT), for her comments and English review.

Conflicts of Interest: The authors declare no conflict of interest.

\section{References}

1. Grace, D. Food Safety in Low and Middle Income Countries. Int. J. Environ. Res. Public Health 2015, 12, 10490-10507. [CrossRef] [PubMed]

2. WHO. WHO Estimates of the Global Burden of Foodborne Diseases: Foodborne Disease Burden Epidemiology Reference Group 2007-2015; WHO: Geneva, Switzerland, 2015.

3. VFA. Vietnam Food Administration: Report on Food Poisoning Outbreaks in Vietnam. Available online: http:/ / www.vfa.gov.vn/ngo-doc-thuc-pham/bao-cao-vu-ngoc-doc-thuc-pham.html (accessed on 28 December 2017).

4. Havelaar, A.H.; Galindo, A.V.; Kurowicka, D.; Cooke, R.M. Attribution of foodborne pathogens using structured expert elicitation. Foodborne Pathog. Dis. 2008, 5, 649-659. [CrossRef] [PubMed]

5. OECD. Meat Consumption (Indicator). Available online: https://data.oecd.org/agroutput/meatconsumption.htm (accessed on 15 November 2017).

6. EFSA. Opinion of the Panel on Biological Hazards on a request from the European Commission on a quantitative microbiological risk assessment on Salmonella in meat: Source attribution for human salmonellosis from meat. EFSA J. 2008, 625, 1-32.

7. Pires, S.M.; Vieira, A.R.; Hald, T.; Cole, D. Source attribution of human salmonellosis: An overview of methods and estimates. Foodborne Pathog. Dis. 2014, 11, 667-676. [CrossRef] [PubMed]

8. Lapar, M.; Tiongco, M. Private standards in pork value chains: Role, impact and potential for local innovation to improve food safety and enhance smallholder competitiveness. Farm Policy J. 2011, 8, 39-53.

9. Wood, R.L.; Pospischil, A.; Rose, R. Distribution of persistent Salmonella Typhimurium infection in internal organs of swine. Am. J. Vet. Res. 1989, 50, 1015-1021. [PubMed]

10. Boyen, F.; Haesebrouck, F.; Maes, D.; Van Immerseel, F.; Ducatelle, R.; Pasmans, F. Non-typhoidal Salmonella infections in pigs: A closer look at epidemiology, pathogenesis and control. Vet. Microbiol. 2008, 130, 1-19. [CrossRef] [PubMed]

11. Rostagno, M.H.; Callaway, T.R. Pre-harvest risk factors for Salmonella enterica in pork production. Food Res. Int. 2012, 45, 634-640. [CrossRef]

12. Tran, T.P.; Ly, T.L.; Nguyen, T.T.; Akiba, M.; Ogasawara, N.; Shinoda, D.; Okatani, T.A.; Hayashidani, H. Prevalence of Salmonella spp. in pigs, chickens and ducks in the Mekong Delta, Vietnam. J. Vet. Med. Sci. 2004, 66, 1011-1014. [CrossRef] [PubMed]

13. Vo, A.T.; van Duijkeren, E.; Fluit, A.C.; Heck, M.E.; Verbruggen, A.; Maas, H.M.; Gaastra, W. Distribution of Salmonella enterica serovars from humans, livestock and meat in Vietnam and the dominance of Salmonella Typhimurium phage type 90. Vet. Microbiol. 2006, 113, 153-158. [CrossRef] [PubMed] 
14. Dang-Xuan, S.; Nguyen-Viet, H.; Unger, F.; Pham-Duc, P.; Grace, D.; Tran-Thi, N.; Barot, M.; Pham-Thi, N.; Makita, K. Quantitative risk assessment of human salmonellosis in the smallholder pig value chains in urban of Vietnam. Int. J. Public Health 2017, 62, 93-102. [CrossRef] [PubMed]

15. Le Bas, C.; Tran, T.H.; Nguyen, T.T.; Dang, D.T.; Ngo, C.T. Prevalence and epidemiology of Salmonella spp. in small pig abattoirs of Hanoi, Vietnam. Ann. N. Y. Acad. Sci. 2006, 1081, 269-272. [CrossRef] [PubMed]

16. Takeshi, K.; Itoh, S.; Hosono, H.; Kono, H.; Tin, V.T.; Vinh, N.Q.; Thuy, N.T.; Kawamoto, K.; Makino, S. Detection of Salmonella spp. isolates from specimens due to pork production chains in Hue city, Vietnam. J. Vet. Med. Sci. 2009, 71, 485-487. [CrossRef] [PubMed]

17. Yokozawa, T.; Dang-Xuan, S.; Nguyen-Viet, H.; Lapar, L.; Makita, K. Transition of Salmonella prevalence in pork value chain from pig slaughterhouses to markets in Hung Yen, Vietnam. J. Vet. Epidemiol. 2016, 20, 51-58. [CrossRef]

18. Phan, T.T.; Khai, L.T.; Ogasawara, N.; Tam, N.T.; Okatani, A.T.; Akiba, M.; Hayashidani, H. Contamination of Salmonella in retail meats and shrimps in the Mekong Delta, Vietnam. J. Food Prot. 2005, 68, 1077-1080. [CrossRef] [PubMed]

19. Thai, T.H.; Hirai, T.; Lan, N.T.; Yamaguchi, R. Antibiotic resistance profiles of Salmonella serovars isolated from retail pork and chicken meat in North Vietnam. Int. J. Food Microbiol. 2012, 156, 147-151. [CrossRef] [PubMed]

20. Den Aantrekker, E.D.; Boom, R.M.; Zwietering, M.H.; Schothorst, M. Quantifying recontamination through factory environments-a review. Int. J. Food Microbiol. 2003, 80, 117-130. [CrossRef]

21. Redmond, E.C.; Griffith, C.J. Consumer food handling in the home: A review of food safety studies. J. Food Prot. 2003, 66, 130-161. [CrossRef] [PubMed]

22. Grace, D.; Makita, K.; Kang'ethe, E.K.; Bonfoh, B. Safe Food, Fair Food: Participatory risk analysis for improving the safety of informally produced and marketed food in sub-Saharan Africa. Rev. Africaine Santé Prod. Anim. 2010, 8, 3-11.

23. Makita, K.; Desissa, F.; Teklu, A.; Zewde, G.; Grace, D. Risk assessment of staphylococcal poisoning due to consumption of informally-marketed milk and home-made yoghurt in Debre Zeit, Ethiopia. Int. J. Food Microbiol. 2012, 153, 135-141. [CrossRef] [PubMed]

24. Michael, C.N.; Strojan, C. Risk Assessment: Logic and Measurement, 1st ed.; CRC Press: Chelsea, MI, USA, 1998; ISBN 9781575040486.

25. Nga, N.T.D.; Huyen, N.T.T.; Hung, P.V.; Ha, D.N.; Long, T.V.; Be, D.T.; Unger, F.; Lapar, L. Household pork consumption behaviour in Vietnam: Implications for pro-smallholder pig value chain upgrading. In Proceedings of the Tropentag 2015 Conference, Berlin, Germany, 16-18 September 2015.

26. ACIAR. Reducing Disease Risks and Improving Food Safety in Smallholder Pig Value Chains in Vietnam. Available online: http:/ / aciar.gov.au/project/lps / 2010/047 (accessed on 15 November 2017).

27. Dang-Xuan, S. Quantifying Salmonella spp. in pig slaughterhouses and pork markets associated with human health in Hung Yen, Vietnam. Master's Thesis, Chiang Mai University, Chiang Mai, Thailand, September 2013.

28. Ravishankar, S.; Zhu, L.; Jaroni, D. Assessing the cross contamination and transfer rates of Salmonella enterica from chicken to lettuce under different food-handling scenarios. Food Microbiol. 2010, 27, 791-794. [CrossRef] [PubMed]

29. ISO-6579. International Standard Organization: Microbiology of Food and Animal Feeding Stuffs-Horizontal Method for the Detection of Salmonella spp.; ISO: Geneva, Switzerland, 2002.

30. ISO/TS-6579-2. Microbiology of Food and Animal Feed-Horizontal Method for the Detection, Enumeration and Serotyping of Salmonella. Part 2: Enumeration by a Miniaturized Most Probable Number Technique; ISO: Geneva, Switzerland, 2012.

31. Cochran, W.G. Estimation of bacterial densities by means of the "most probable number". Biometrics 1950, 6, 105-116. [CrossRef] [PubMed]

32. Makita, K.; Mahundi, E.; Toyomaki, H.; Ishihara, K.; Sanka, P.; Kaaya, E.J.; Kurwijila, L.R. Risk assessment of campylobacteriosis due to consumption of roast beef served in beer bars in Arusha, Tanzania. J. Vet. Epidemiol. 2017, 21, 55-64. [CrossRef]

33. Marie-Laure, D.M.; Christophe, D. Fitdistrplus: An R Package for Fitting Distributions. Available online: https:/ / cran.r-project.org/web/packages/fitdistrplus/vignettes/paper2JSS.pdf (accessed on 15 June 2016). 
34. Klontz, K.C.; Timbo, B.; Fein, S.; Levy, A. Prevalence of selected food consumption and preparation behaviors associated with increased risks of foodborne disease. J. Food Prot. 1995, 58, 927-930. [CrossRef]

35. Darcy, H. Part I. Characterization of The Organisms Involved in Foodborne Illness: Nontyphoid Salmonella. In International Handbook of Foodborne Pathogens, 1st ed.; Marianne, D.M., Jeffrey, W.B., Eds.; Marcel Dekker: New York, NY, USA, 2003; pp. 146-158. ISBN 0-8247-0685-4.

36. Barakat, S.; Mahmoud, M. Salmonella-A Dangerous Foodborne Pathogen, 1st ed.; InTech: Rijeka, Croatia, 2012.

37. Bloomfield, S.F.; Aiello, A.E.; Cookson, B.; O’Boyle, C.; Larson, E.L. The effectiveness of hand hygiene procedures in reducing the risks of infections in home and community settings including handwashing and alcohol-based hand sanitizers. Am. J. Infect. Control 2007, 35, S27-S64. [CrossRef]

38. Barker, J.; Naeeni, M.; Bloomfield, S.F. The effects of cleaning and disinfection in reducing Salmonella contamination in a laboratory model kitchen. J. Appl. Microbiol. 2003, 95, 1351-1360. [CrossRef] [PubMed]

39. Burton, M.; Cobb, E.; Donachie, P.; Judah, G.; Curtis, V.; Schmidt, W.P. The effect of handwashing with water or soap on bacterial contamination of hands. Int. J. Environ. Res. Public Health 2011, 8, 97-104. [CrossRef] [PubMed]

40. Hoque, B.A.; Mahalanabis, D.; Pelto, B.; Alam, M.J. Research methodology for developing efficient handwashing options: An example from Bangladesh. J. Trop. Med. Hyg. 1995, 98, 469-475. [PubMed]

41. Soares, V.M.; Pereira, J.G.; Viana, C.; Izidoro, T.B.; Bersot, L.S.; Pinto, J.P. Transfer of Salmonella Enteritidis to four types of surfaces after cleaning procedures and cross-contamination to tomatoes. Food Microbiol. 2012, 30, 453-456. [CrossRef] [PubMed]

42. Omer, M.K.; Hauge, S.J.; Ostensvik, O.; Moen, B.; Alvseike, O.; Rotterud, O.J.; Prieto, M.; Dommersnes, S.; Nesteng, O.H.; Nesbakken, T. Effects of hygienic treatments during slaughtering on microbial dynamics and contamination of sheep meat. Int. J. Food Microbiol. 2015, 2, 194-197. [CrossRef] [PubMed]

43. Sohaib, M.; Anjum, F.M.; Arshad, M.S.; Rahman, U.U. Postharvest intervention technologies for safety enhancement of meat and meat based products: A critical review. J. Food Sci. Technol. 2016, 53, 19-30. [CrossRef] [PubMed]

44. Shen, J.; Zhao, B.X.; Li, T.; Ban, H.Q.; Tian, L.; Ge, Y.L.; Chen, T.Y.; Li, S.Y.; Zhang, L.B. Microbial presence on kitchen dishcloths in Chinese households. Biomed. Environ. Sci. 2014, 27, 978-981. [CrossRef] [PubMed]

45. Jimenez, S.M.; Tiburzi, M.C.; Salsi, M.S.; Moguilevsky, M.A.; Pirovani, M.E. Survival of Salmonella on refrigerated chicken carcasses and subsequent transfer to cutting board. Lett. Appl. Microbiol. 2009, 48, 687-691. [CrossRef] [PubMed]

46. Yoon, H.; Lee, J.Y.; Suk, H.J.; Lee, S.; Lee, H.; Lee, S.; Yoon, Y. Modeling to predict growth/no growth boundaries and kinetic behavior of Salmonella on cutting board surfaces. J. Food Prot. 2012, 75, 2116-2121. [CrossRef] [PubMed]

47. Cliver, D.O. Cutting boards in Salmonella cross-contamination. J. AOAC Int. 2006, 89, 538-542. [PubMed]

48. Tang, J.Y.; Nishibuchi, M.; Nakaguchi, Y.; Ghazali, F.M.; Saleha, A.A.; Son, R. Transfer of Campylobacter jejuni from raw to cooked chicken via wood and plastic cutting boards. Lett. Appl. Microbiol. 2011, 52, 581-588. [CrossRef] [PubMed]

49. Langiano, E.; Ferrara, M.; Lanni, L.; Viscardi, V.; Abbatecola, A.M.; De Vito, E. Food safety at home: Knowledge and practices of consumers. Z. Gesundh. Wiss. 2012, 20, 47-57. [CrossRef] [PubMed]

50. Jensen, D.A.; Friedrich, L.M.; Harris, L.J.; Danyluk, M.D.; Schaffner, D.W. Quantifying transfer rates of Salmonella and Escherichia coli O157:H7 between fresh-cut produce and common kitchen surfaces. J. Food Prot. 2013, 76, 1530-1538. [CrossRef] [PubMed]

51. Miranda, R.C.; Schaffner, D.W. Longer contact times increase cross-contamination of Enterobacter aerogenes from surfaces to food. Appl. Environ. Microbiol. 2016, 82, 6490-6496. [CrossRef] [PubMed]

52. Medeiros, L.C.; Hillers, V.N.; Kendall, P.A.; Mason, A. Food safety education: What should we be teaching to consumers? J. Nutr. Educ. 2001, 33, 108-113. [CrossRef]

53. Carrasco, E.; Morales-Rueda, A.; García-Gimeno, R.M. Cross-contamination and recontamination by Salmonella in foods: A review. Food Res. Int. 2012, 45, 545-556. [CrossRef]

54. Gorman, R.; Bloomfield, S.; Adley, C.C. A study of cross-contamination of food-borne pathogens in the domestic kitchen in the Republic of Ireland. Int. J. Food Microbiol. 2002, 76, 143-150. [CrossRef]

(C) 2018 by the authors. Licensee MDPI, Basel, Switzerland. This article is an open access article distributed under the terms and conditions of the Creative Commons Attribution (CC BY) license (http://creativecommons.org/licenses/by/4.0/). 